\title{
Indigenismos e Americanismos na Conquista das Américas
}

\author{
Bruno José Betti Galasso*
}

Resumo: Neste trabalho apresenta-se um breve estudo da filologia e a lingüística americana, através dos vocabulários bilíngües compostos da época colonial. Conquanto tenha sido apreciado seu valor como dicionários das línguas ameríndias, até agora não se valorizou sua especificidade como obras lexicográficas. Os repertórios indigenistas deveriam ser levados em conta na hora de elaborar uma história crítica da lexicografia americana. Não há dúvida de que as contribuições dos missionários foram decisivas para a história da cultura e da lingüistica porque codificaram pela primeira vez o léxico das línguas aborígenes de América, e o transladaram aos idiomas português e espanhol. Portanto, além de contribuir ao conhecimento desta parcela pouco explorada da lexicografia, nosso propósito consiste em aproveitar a bibliografia como fonte para descobrir o estado das línguas européias na América, mesmo que não sejam dicionários léxicos.

Palavras-chave: Indigenismo, Léxico, América.

Abstract: This work presents a brief study of American philology and linguistics by means of the analysis of bilingual vocabularies (glossaries) established during the colonial period. Although its value in terms of dictionaries of Amerindian languages has been recognized, its specific value as lexicographical works has not. The indigenous repertoires should have been taken into consideration when preparing a critical history of American lexicography. The contributions from the missionaries were undoubtedly decisive for the history of culture and linguistics because they codified for the very first time the vocabulary of different aboriginal languages in America and translated them into the Portuguese and Spanish languages. Therefore, in addition to contributing towards the discovery and knowledge of this virtually unexplored part of our lexicography, our objective consists in taking advantage of this bibliography as a source for discovering the current state of European languages in America, even if they are not lexicon dictionaries.

Keywords: Indigenism, Lexicon, America.

* Mestrando do Programa de Pós-Graduação em Integração da América Latina - PROLAM/USP. E-mail: brunogalasso@ uol.com.br. Recebido em 10/08/07 e aceito em 11/11/07. 


\section{Introdução}

A partir da chegada de Colombo na América e das conquistas que se seguiram - subjugando os povos que aqui viviam se deu o rompimento do longo isolamento do Novo Mundo em relação ao Velho Mundo.

O Estado brasileiro estruturou-se em terras de inúmeros grupos étnicos. Lugar em que, inicialmente, aportaram portugueses, franceses e holandeses e, logo após, sob cativeiro, membros de grupos étnicos situados no continente africano. Os povos indígenas seguramente não tinham perspectiva alguma de se tornarem parte integrante de uma comunidade estrangeira, mas pela miscigenação, através do tempo, resultou em uma sociedade singular e distinta das que a originou: a sociedade brasileira (RIBEIRO, 1995).

Não obstante, a inegável presença de palavras de origem indígena na fala dos diferentes países americanos não deixa lugar a discussão sobre a relevância que este nível lingüístico atinge como produto do contacto lingüístico e cultural entre ambos os povos. Mas a importância quantitativa destes empréstimos fica reduzida, em muitos casos, quando se comprova que boa parte dos termos inventariados nos mais reconhecidos dicionários de americanismos gozam de escassa ou nula vitalidade entre os americanos.

Exige-se, então, certa prudência na valoração do léxico indígena como elemento diferencial na construção dos idiomas falados nas Américas, ainda que o estado atual da investigação recupere sua importância dialectal, sem esquecer a enorme distância que separa a realidade lingüística dos dicionários, bem como o acúmulo de palavras desusadas e desconhecidas para a comunidade em geral.

\section{Vida e uso dos indigenismos no século XVI}

A incorporação progressiva de palavras americanas nos idiomas dos conquistadores representa o resultado de um processo de denominaçáo, iniciado no momento do descobrimento e destinado a suprir as limitaçóes dos idiomas português e espanhol para designar os seres e os objetos descobertos a partir das culturas indígenas americanas tão estranhos aos olhos europeus e sem as quais seria muito difícil dar nomes adequados a estas coisas.

Se, em um primeiro momento ou problema lingüístico se resolveria com ou recurso léxico patrimonial, com clara inclinação para os termos de 
procedência árabe, logo a língua dos conquistadores revela-se insuficiente ante a enormidade da natureza e da inovadora cultura americana: espécies de fauna e flora, objetos e instrumentos relacionados com o cotidiano, com suas práticas agrícolas ou artesanais, sua vestimenta ou alimentação, sem esquecer os aspetos relativos à organização social ou às crenças religiosas dos diferentes povos, conformam todo um universo conceitual representativo de formas de vida diferentes que exigia ser novamente nomeado.

Não bastaram então as analogias, os procedimentos léxico-genéticos nem os usos metafóricos da linguagem; a ausência de equivalências léxicas, a inexatidão das traduções ou os contínuos equívocos a que dá lugar a aplicação dos mesmos nomes a realidades bem diferentes entre si, são algumas das causas fundamentais que explicam e justificam essa maior aproximação aos vocábulos da outra língua, nem sequer o inesgotável esforço criador destes primeiros homens bastou para captar uma realidade que, sem o recurso ao indígena, teria permanecido inédita.

Já nos diários dos navegadores registram-se as palavras canoa, rede, maltrates, cacique. Lindo (2005) assinalou o valor mais simbólico que real da obra colombina como primeiro depoimento da entrada de indigenismos antilhanos no espanhol, graças à escassa difusão atingida pela obra, ante a abundante documentação oficial produzida na América e ao seu intercâmbio fluído com a emanada das autoridades metropolitanas. Boyd-Bowman (1972, p. 218) documentou a presença de muitos indígenismos no léxico oficial da Secretaria Real, entre 1449 e 1520; uns 20 indigenismos encontra Lindo (2005), nas mesmas fontes, sem explicações a respeito de seu conteúdo semântico.

Boyd-Bowman (1972) explicou-o:

o desejo de propriedade lingüística e a conseguinte indecisão para dar nomes às coisas que não podem reconhecer, se complica no ânimo dos descobridores com o preconceito de se achar cerca das terras visitadas e descritas por Marco Pólo [...] Assim se explica a inclinação pelas vozes árabes para nomear as coisas novas (BOYD-BOWMAN, 1972, p. 234).

Os exemplos dos primeiros tempos, que ilustram sobre este fundamental 
problema lingüístico, não faltam. Muito conhecido é o mal-estar que produz no Almirante a falta de referentes peninsulares que sirvam de base comparativa para o novo mundo que trata de descrever; ou a indecisão mostrada ao dar nome à nova natureza; abundantes são também os depoimentos cronísticos que nos falam desse interesse por precisar o conteúdo referencial daqueles vocábulos de nossa própria língua que tinham adquirido matizes ou significados novos no processo de adaptação ao mundo americano.

O contato lingüístico que desde os inícios da conquista se estabelece na busca do entendimento mútuo teria de favorecer então a aquisição dos indigenismos para encher essas áreas léxicas vazias, ante a incapacidade designativa do vocabulário patrimonial, ainda mais quando fatores de índole social permitem essa progressiva aproximação idiomática e o transpasse das vozes de uma língua a outra.

Silva Neto (1963) destacou o papel fundamental que as relações de trabalho, estabelecidas pelo regime de encomendas, e a mestiçagem, fruto das uniōes cada vez mais numerosas entre europeus e índias tiveram na adoção de termos para os diferentes procedimentos empregados na compreensão da nova realidade.

Boyd-Bowman (1972, p. 234) alega no Diário colombino: "algumas árvores eram da natureza de outros que há em Castilla, portanto tinha muito grande diferença, e as outras árvores de outras maneiras eram tantos, que não há pessoa que o possa dizer nem assemelhar a outros de Castilla".

Alvar (2003, p. 45) analisou esta vacilação na aplicação dos termos da própria língua. Boyd-Bowman (1972, p. 233) comenta assim mesmo estes fatos e assinala, a título de exemplo, entre outros, como a voz peru foi chamada primeiro de galinha, depois galinha da terra, galo de papada e, finalmente, peru. Alvar (1990) diz:

trouxeram muitas codornas e pombas e muitas outras aves que chamamos de faisão; mas não o são, já que em seu gentil sabor não são inferiores às boas perdizes e tal têm o plumagem, e são maiores.(...) O que chamamos de pepinos não o são, ainda que lhes deram esse nome, nem têm muita semelhança de pepinos, já que são alongados, é têm uns trechos ou divisões. (ALVAR, 1990, p. 201) 
A atenção ao léxico indígena é um dos recursos mais efetivos nesse caminho para a intercomunicação e, como manifestou Ramírez (1991), deu-se desde o momento mesmo em que se póe em marcha o primeiro dos mecanismos destinados à uniáo entre os dois povos encontrados:

Durante muito tempo, a comunicação entre europeus e índios não se realizou unicamente por meio de gestos, senão mediante o emprego, por parte dos interlocutores, do mais ou menos reduzido número de palavras que cada qual conhecia da língua do outro, ou seja, numa língua mista.

Os grandes conquistadores e descobridores estiveram desde o princípio e no princípio do mundo americano. Quando iniciam as empresas que inscrevê-los-ão na história são já veteranos e o prestígio que essa experiência implica, se deve, entre outras coisas, aos antilhanismos e caribismos que fazem parte de seu léxico, e que adquirem assim caráter de símbolos. Sua fala distinguir-se-á da dos que cheguem mais tarde.

Compreende-se assim a importância, tantas vezes assinalada, das chamadas línguas do primeiro contato como fonte principal dos empréstimos que se incorporam à língua. $\mathrm{O}$ encontro com as grandes culturas pré-hispânicas, social e culturalmente mais desenvolvidas conseguem dar um novo impulso à influência de indigenismos no espanhol, especialmente no caso do México, a primeira à que tiveram acesso os descobridores. Para entáo, o volume léxico proporcionado por estas línguas durante o contato antilhano tinhase incorporado de maneira definitiva à fala dos conquistadores anulando a possível concorrência que os termos autóctones ofereciam:

Almeida (2005) considerou a escassa influência fonética e fonológica exercida pelas línguas indígenas como resultado de uma europeizaçáo que afeta fundamentalmente a população mestiça, e em menor medida à índia, circunstância que permite contemplar o fato desde uma perspectiva sociolingüística que encontra a explicação na tendência que se exerce para a variedade mais prestigiosa:

como provam as observaçóes atuais, os meninos contam, pelo geral, com uma sensibilidade lingüística suficiente para distinguir a variedade autêntica de um dos pais e a deficiência do outro, e se orientam seguindo as normas sociais do respeito, para aquela variedade que tem mais prestígio social (ALMEIDA, 2005, p. 25). 
No nível léxico, no entanto, tais critérios não podem ser aplicados precisamente por se tratar de um vocabulário geralmente compartilhado por ambas partes.

Citando os exemplosencontradosemfonteshistóricas ou em documentação oficial, depoimento excepcional do caráter patrimonial adquirido pelos empréstimos antilhanos, oferecem às próprias obras lexicográficas americanas aparecidas nos dois primeiros séculos de colonização, como o Vocabulário em língua castelhana e mexicana, do franciscano Alonso de Molina, que em suas duas sucessivas edições incorpora um rico volume léxico de origem indo-americano nas entradas da secção castelhana ou no Vocabulário manual das línguas castelhana e mexicana, de Pedro Areias, dicionário que, a modo de guia de conversa, transcreve unidades comunicativas nas que as palavras antilhanas se incluem como parte da tradução espanhola da língua indígena (RAMÍREZ, 1991).

Existem, no entanto, exceções. No final do século XVI assistimos à substituição, total ou parcial, de muitos destes termos, que após uma longa concorrência lingüística com as que proporciona a língua do território acabam por ceder ante esta última. Zamora (1982) explica-o como conseqüência derivada, em parte, do fluxo migratório cada vez maior que chega diretamente da Europa às novas terras descobertas.

Apesar das observaçóes anteriores, o exame histórico dos indigenismos mostra um processo de regressão, cada vez mais acusado à medida que avançam nos séculos, que leva ao total desaparecimento de muitos destes termos, substituídos ou não por seus equivalentes patrimoniais, ou à reclusão de um bom número deles a falas locais ou regionais. Agnolin (2004) uniu às próprias condições que impóe a realidade extralingüística, com o avanço social e cultural que implica a perda dos referentes, causas sociolingüísticas que, baseadas na superioridade cultural do conquistador, impedem a retenção de muitos destes termos.

Alvar (1990) destacou a sobrevivência atual destes indigenismos antilhanos nas falas mexicanas e centro-americanas, que substituem aos equivalentes da língua originaria do território, e recorda a vitalidade e sobrevivência destes termos. 
Comenta Lindo (2005) a respeito:

fica claro que os indigenismos que chegam aos papéis, sejam estes os que forem, não foram todos os manejados realmente pela língua falada daqueles tempos em que o bilingüismo devia promover com mais afinco. Não é uma hipótese. Ainda que o padrão que se estabelece ao longo dos séculos seguintes é de franca diminuição de indigenismos, a língua viva de hoje ou de tempos relativamente próximos a nós conservou termos de fauna e flora, sobretudo, que não se registram nesses documentos. (LINDO, 2005, p. 287)

Alvar (1990) ressaltou a importância das obras escritas neste período ao comentar o observado na mais temporã de Fernández de Oviedo. Se das 76 bases léxicas de origem indígena que registra na História geral e natural, a percentagem de palavras conservadas na fala do México, América Central e outras áreas hispânicas, mal atinge um terço. $\mathrm{O}$ autor sente falta de outros vocábulos de clara vigência sincrônica não documentados na obra, dados que se justificam ao se ter em conta a cronologia da obra e as circunstâncias históricas e sociais nas que esta se inscreve. Segundo o autor:

achamos que os conquistadores e colonizadores adotaram palavras indígenas pelas razóes de prestígio e necessidade mas, uma vez suprida a necessidade, que foi o critério mais importante na aceitação de indigenismos, achamos que se produziu um processo de regressão e se procurou novamente um vocábulo europeu, como uma espécie de lealdade à língua materna. (ALVAR, 1990, p. 21)

Desta maneira, desde o século XVII, a tendência geral será a de limitar a presença destas palavras àqueles casos nos que a razáo fundamental do empréstimo léxico é manifesta, isto é, quando a ausência de significantes ou equivalentes na língua faz estritamente necessária sua acolhida.

Os anos finais do século XVI são cruciais como período de trânsito que marca o passo de uma etapa inicial, na que a expansão léxica se realiza de maneira efetiva como resultado de um bilingüismo cada vez mais extenso, 
sem esquecer o papel fundamental que neste sentido joga a adoção e utilização das línguas e uma segunda etapa que marca o início do retrocesso destas vozes gerais relegadas ou esquecidas, ante o empuxo dos vocábulos da própria língua. É este momento também onde melhor pode-se apreciar a luta estabelecida entre os termos indigenistas e europeus que tratam de se impor.

Em muitos casos os indigenismos podem ser não aditivos, mas substitutivos. Não se tomam das línguas indígenas para nomear o novo senão para substituir a palavras que já se conheciam pelos conquistadores.

\section{O peso lexicográfico dos indigenismos}

A importância lexicográfica dos indigenismos, desde os primeiros glossários aparecidos no século XVII até as mais recentes compilações, confirma a função diferenciadora destes vocábulos.

$\mathrm{O}$ interesse dos lexicógrafos pelo exótico americano e o critério contrastante com clara subordinação à norma peninsular nos primeiros momentos favorecem a inclusão do léxico indigenista e o reconhecimento explícito de sua extensão diatópica.

A obra de Fray Pedro Simón de 1627 (MANTILLA RUIZ, 1986), pioneira na distinção do uso regional dos vocábulos , e ao dicionário de Manuel José de Ayala, composto entre 1751 e 1777 (AGNOLIN, 2004), segue no final do setecentos (1786-1789) o Vocabulário de Antonio de Alcedo (1967), no qual a soma dos indigenismos registrados ascende a um total de 400 , dos que boa parte não ultrapassa o âmbito regional.

Terá que esperar até o século XIX para ver aparecer no panorama lexicográfico americano as primeiras obras realizadas sob uma perspectiva dialetológica que assume a função de dotar de sistematicidade aos usos léxicos não usuais das distintas regióes americanas. Como comenta Silva Neto (1963):

os dicionários de regionalismos, ainda que redigiam-se para censurar barbarismos, vulgarismos e solecismos desde, meados do século XIX até o último quarto do $\mathrm{XX}$, respondiam também ao desejo inconfesso de 
encontrar num dicionário palavras queridas de cada regiáo, sem alterar o predomínio documental e normativo do dicionário acadêmico. (SILVA NETO, 1963, p. 152)

Alguns autores de dicionários, por toda a América Latina, trataram de recolher as palavras da fala popular de seus respectivos países não admitidas pela Academia. Igual importância léxica apresentam os pequenos glossários com os que começam a se introduzir vozes indígenas.

A proliferação destes dicionários e repertórios lexicográficos obedece, como produto de uma época na que a unidade da língua se questiona, a uma finalidade normativa que, em muitos casos, corrigem os supostos barbarismos ou provincialismos, também de origem indígena.

Em todos eles, a consideração do dialetal como fator identificador dos diferentes povos e o valor etnológico que os indigenismos adquirem como reflexo do próprio mundo fazem dar cabimento a um grande número de vozes indigenistas não sempre validadas pelo uso. Esta tendência manifesta nos dicionários e desemboca na criação de obras de caráter etimológico.

A incorporação de americanismos em obras de caráter geral, não se afasta dos critérios seguidos em séculos precedentes. Estas obras eram elaboradas com a intenção expressa de caracterizar diatopicamente as diferentes regióes americanas, sobretudo desde que, no século XIX, Vicente Salvá reclamasse para as variedades léxicas americanas igual tratamento que o recebido pelo resto dos regionalismos do espanhol.

A atenção prestada aos vocábulos próprios da realidade americana que táo claramente ilustrasse o lexicógrafo, os frutos do campo que formam seu principal sustento, das plantas e árvores que lhes são mais conhecidos, as palavras que empregam em sua agricultura e artefatos, e sobretudo no benefício das minas de ouro e prata e o esforço por registrar a procedência regional dos termos que inventariava, fazem dos dicionários uma obra precursora que inicia o caminho que levará a uma cada vez mais crescente incorporaçáo de indigenismos de caráter regional que bem podem servir para uma apreciação global da diversidade, ainda léxica que estes vocábulos.

Também os dicionários gerais de americanismos elaborados no século XX contribuem por um critério histórico na seleção de seus respectivos catálogos 
lexicográficos que justifica a enorme presença de vozes indígenas que cabem neles. Inclusive, ainda que se revisam os critérios e indica-se a redução, como no caso de Neves, de vozes antiquadas, a verdade é que aparecem termos de fauna e flora próprias do mundo americano com pouco uso atual.

Com tudo, há exceções. Alguns dicionários também se afastam dos critérios manejados por seus predecessores e recolhem tão somente as palavras de origem indigenista de grande extensão geográfica e ainda aquelas que fazem parte do patrimônio comum da língua espanhola, mas se sente falta aquelas outras de contexto geográfico mais reduzido.

A bibliografia crítica destes dicionários trouxe de novo a discussão a respeito do conceito de americanismo e do modelo lexicográfico, exclusivo ou contrastante, com o que deve se abordar a elaboração destes repertórios léxicos do europeu. Procura-se uma nova forma lexicográfica de fazer os dicionários, centrada num caráter diferencial semântico e uma validade pragmática.

Certamente que não é excessivo nem surpreendente o número de indigenismos léxicos americanos que se instalaram já, com pleno direito, nos dicionários. Mas é bem mais elevado o número de indigenismos léxicos que vivem hoje no espanhol falado, por exemplo, em amplas regióes da América, correspondentes a um ou a vários países, e mais ainda o de indigenismos que se usam cotidianamente em pequenas comunidades onde os idiomas americanos convivem com o europeu.

\section{A penetração de indigenismos no século XVI}

A presença de termos indígenas, determinante para alguns na conformação das peculiaridades do vocabulário americano resulta lógica e mais relevante ali onde as populaçóes indígenas e européias tiveram e mantiveram maior coexistência entre suas culturas diferentes, isto é, em lugares em que o contato multicultural foi mais prolongado.

Os empréstimos léxicos índios no espanhol colonial devem enquadrar-se, portanto, no contexto americano do momento, onde a convivência cultural só permite assegurar, ali onde as relações pudessem ser mais estreitas, um emprego indígena de uma língua, sem possibilidade alguma de influência na língua dominadora. No entanto, a diversidade lingüística e os extensos 
territórios que se iam colonizando exigiam contínuas recorrências aos intérpretes quando não há terminologia européia como forma de designação imediata.

A própria meta da colonização precisava de um contato verbal que acaba por se impor, seja pela necessidade quotidiana de intercomunicação entre colonizadores europeus e indígenas do lugar, seja por objetivos imperialistas ou religiosos, nos que tanto a Coroa como a Igreja se sentiam obrigados para atingi-los com a necessidade que lhes impunham os avanços na conquista e na evangelização das tribos. Assim, as línguas indígenas mais gerais se sobrepunham às variedades menos extensas por mandato dos Reis, com editos e cédulas que estabelecem a aprendizagem das línguas da terra (ALVAR, 1990).

Isto não quer dizer que se negue a ação das línguas indígenas, senão que se valorize em seus justos termos.

Mantilla Ruiz (1986, p. 112) recolhe exemplos da variedade lingüística indígena nos cronistas, à que se somam os nomes com os que os europeus se referem a essas mesmas realidades: "valem-se de pás formadas de pau duríssimo, que uns chamam aranco, outros macana, e cada nação segundo sua lingua lhe dá seu nome."

A necessidade de nomear as coisas por seu significante autóctone era evidente, pelo modo como os erros se produziam com as adaptaçóes castelhanas, porque mal se podia entender a identidade entre lagarto e caimán ou que a palavra corvo desse nome a tanta variedade de aves, com táo diferentes tamanhos e características.

Os procedimentos de transmissão indigenista foram estudados nas descriçóes e crônicas dos conquistadores e primeiros colonizadores da América. Os agrupamentos sintagmáticos, algumas com especificaçóes geográficas, foram as primeiras em aflorar com a intenção de aclarar a possível ambigüidade que acarretava o emprego de vozes castelhanas na nomeação da realidade indígena.

Os diferentes procedimentos, de equiparação, comparação, longas paráfrases, explicaçóes de sua utilidade, etc., descrevem-se em numerosos estudos, como os de Alvar (2003), Silva Neto (1963), Zamora (1982), etc. Em todos eles os exemplos se sucedem até dar com o uso exclusivo do 
vocabulário indígena, quando a precisão para encontrar um termo com que designar o novo referente levou à adoção completa do indigenismo. $\mathrm{O}$ comentário que Alvar (1990) deduz recorda este caminho que segue a língua dos colonos e dos viajantes, dos soldados e dos clérigos, quando a língua se "aindiza” para chamar com precisão as novas produçóes americanas. Não sem antes passar pelo denominador comum que abarcava todas essas variedades e que coexistiam no sintagma da terra.

Desta maneira, "são da terra as ricas camisas que levavam as donzelas de Cempoal, os huipiles, que por camisa de india traduziria bem exatamente Molina" (ALVAR, 1990, p. 27).

O procedimento de adaptação que se segue reflete, diz Alvar (1990, p. 52), os usos tradicionais e esperados em qualquer língua que entra em contato com outra. Assim aparecem equivalências léxicas, a reduplicação do vocabulário, a adoção completa, como uma voz patrimonial.

Estes procedimentos repetem-se em qualquer cronista. Alvar (1990) recorda esta irrupção de palavras indígenas desde o primeiro momento da conquista, no Diário do Almirante, e exemplifica os esquemas comentados. Além das equivalências léxicas entre palavras patrimoniais e índias, às vezes, a identidade significativa apresenta três formas léxicas:

e por isto os cristáos chamam na Terra Firme á esta fruta figos do mastuerço [...] levou-os estes figos ao Darién, onde os cristãos os semearam daquelas pepitas é em outras muitas partes [...] é aqui chamam-nos papayas [...] e no governo de Nicarágua chamam esta fruta olocotón. (ALVAR, 1990, p. 47)

Não obstante, esta profusão de termos indígenas, com equivalentes léxicos, em muitos casos, obedece a uma demonstração do caráter erudito do próprio cronista mais que a um uso generalizado.

Mas além da enorme motivação devida ao cumprimento da missão evangelizadora que dirigia a atuaçâo destes improvisados lingüistas, uma série de condicionantes políticos e socioculturais confluíram também no alicerce da lingüística americana. Entre eles destacam o renovador espírito renascentista e as crenças do humanismo europeu, a política lingüística da 
Coroa e a implantação da Universidade e da imprensa.

Cronologicamente, a lexicografia bilíngüe americana é anterior à produzida na Europa. Como é natural, o catálogo dos vocabulários europeuameríndios pretende ser exaustivo, e para seu conhecimento contou-se, em primeiro lugar, com os dados que proporcionam os historiadores da época, quem deram boa conta dos textos que se redigiram; náo obstante, pode ocorrer que o paradeiro seja ainda desconhecido ou que se tenham perdido.

O estudo sobre o peso lexicográfico dos indigenismos confirma a enorme distância que existe entre a coleta de dados léxicos e o emprego habitual, motivada pela seleção de umas fontes de caráter histórico e literário, e em muitas ocasióes afastadas no tempo.

No terreno dos indigenismos, nos dicionários elaborados para o espanhol de Cuba e o espanhol de Argentina uma visão sincrônica desvanece a idéia de um dialeto americano carregado de vocábulos índios. Assim a atualidade e o contraste deixam uma nômina escassa de palavras aborígenes, isto é, não há base real prática que fundamente uma diferenciação diatópica forte. Nem sequer, o dicionário acadêmico mostra com total fiabilidade as palavras indígenas, apesar do esforço que realizou ao suprimir determinadas palavras arcaicas ou desconhecidas.

\section{Considerações finais}

A importância da obra radica não só no objetivo missionário de evangelizar os índios através do método franciscano de convivência continuada com a cultura aborígene, senão que se projeta como uma enciclopédia que abarca os conhecimentos etnológicos e lingüísticos de todo um povo.

Pelo seu valor lexicográfico pode-se marcar o período de mudança na atitude, tanto oficial como eclesiástica, para as línguas indígenas, isto é, em meados do século XVI. Por razóes práticas, a aculturação e a intercomunicação entre europeus e índios exigia um conhecimento das denominadas línguas gerais.

Relativamente à construção dos idiomas falados nas Américas, constatase a vigência, tanto teórica como metodológica, que pretende situar em sua justa medida a valoração deste fenômeno como parte do contato de línguas. Se, historicamente, o léxico foi um rasgo diferencial escolhido para 
a dialetalização americana, de novo incorporou-se, nos últimos tempos, este âmbito lingüístico à determinação das características de uma variedade do espanhol e do português do outro lado do Atlântico.

Trata-se de provar, com bases metodológicas fiáveis, a importância da contribuição que as línguas indígenas têm no conjunto do idioma em geral. Assim, se busca provar que os indigenismos seguem representando o conjunto mais numeroso e com maior vitalidade dos empréstimos que o idioma adquiriu na idade moderna. Contudo, os últimos estudos que valorizam a variação diastrática e, inclusive, os diferentes registros, as investigaçóes a respeito do uso dos idiomas europeus nos meios de comunicação e a elaboração de atlas que recolhem as diferenças regionais contribuem com uma visão mais conciliadora e justa do peso deste elemento indígena na língua comum.

É preciso compreender as discursividades literárias enquanto efeitos de sentido e por esta via de reflexão observar as condiçóes de produção próprias de cada uma destas discursividades para descrever os novos sentidos que estão irrompendo.

Quando uma determinada língua é transferida para outro espaço/tempo, inicia-se um processo de constituição da referência da mesma, o que nos leva a entender que uma determinada língua não tem características intrínsecas, sendo, portanto, passível de transformaçooes tanto no que se refere à sua estrutura como em sua significação, pois estes dois aspectos constitutivos de uma língua não são imóveis/fixos (e nem inseparáveis); eles são construídos numa relação em que o ideológico é marcado, estabilizando uma certa relação entre eles. E são as condições em que o discurso é produzido que são constitutivas da materialidade histórico-discursiva da língua. É isto que entendemos por materialidade lingüístico-histórica (ou materialidade discursiva).

As figuras de sintaxe mostram bem o deslizamento de sentido para a língua nacional, quando se mudam as relaçóes entre as palavras nas frases, com o objetivo de "realçar" o pensamento. Porém, este fenômeno de linguagem é mais que um "desvio" de sentido, trata-se de um problema referente à significação da linguagem (no caso, da constituição de sentido para a língua nacional). Portanto, estas mudanças, observadas nas figuras de sintaxe, em relação à ordem das palavras nas frases, têm a ver com o processo histórico 
de transformação da língua portuguesa no Brasil. Estas figuras, desta perspectiva, constroem a referência da língua nacional. Desta perspectiva, vê-se o funcionamento da concepção de linguagem enquanto expressão do pensamento e a linguagem é a representação do pensamento.

Se, por um lado, neste discurso vê-se a produção do efeito da diferença individual em relação ao modo de se escrever (do estilo de escrita individual) e nesse caso o efeito de estilo apaga as reais condições de produção da diferença lingüística que ele explicita. A diferença aqui não está relacionada à construção da língua nacional. Por outro lado coloca em funcionamento sentidos relacionados à língua nacional, evidenciando a língua construída em condições históricas e ideológicas específicas, ultrapassando o efeito da evidência ideológica de que o estilo está relacionado ao que é individual, ao que é próprio de cada um, pensando. o estilo no interior de questóes políticas referentes à instituição da língua nacional. 


\section{Referências Bibliográficas}

AGNOLIN, Adone. Reduzir a palavra indígena: mecanismos e peculiaridades da política lingüística jesuítica na catequese americana do século XVI. In: Congresso Nacional da Associação Brasileira de Antropologia. Olinda: 2004.

ALMEIDA, Rita Heloísa. O diretório dos indios. Brasília: UNB, 2005.

ALVAR, Manuel. Americanismos en la historia de Bernal Díaz del Castillo. Madri: Ediciones de Cultura Hispánica, 1990.

. La lengua como libertad y otros estudios. Madrid: Ediciones Cultura Hispánica, 2003.

BOYD-BOWMAN, Peter. Léxico hispanoamericano del siglo XVI. Londres: [s.n.], 1972.

LINDO, Luis Antonio. Sensibilidade e valor na criação do léxico americano. Cadernos do CNLF, v. IX, 2005.

MANTILLA RUIZ, Luis Carlos. La tabla para la inteligencia de algunos vocablos. Anexo a su obra Noticias Historiales, publicadas con el título de Fray Pedro Simón y su vocabulario de americanismos (1627). Bogotá: Ed. facsímil, ICC, 1986.

MORÍNIGO, Marcos A. Diccionario de americanismos. Barcelona: 1985. . Las voces guaraníes del diccionario académico. Buenos Aires: 1993.

RAMIREZ, María Vaquero. Español de América y lenguas indígenas. Estudios de Lingüística, 1991.

RIBEIRO, Darcy. O povo brasileiro: a formação e o sentido do Brasil. São Paulo: Companhia das Letras, 1995.

SILVA NETO, Serafim. Introdução ao estudo da língua portuguesa no Brasil. Rio de Janeiro: INL, 1963.

ZAMORA, Juan Clemente. Amerindian loanwords in general and local varieties of American Spanish. Word, v. 33, n. 1-2, p. 159-171, abr./agosto. 1982. 